\title{
POEMS 증후군 환자의 다발성 신경병증에 대한 초기 전기생리학적 소견: 증례보고
}

전소연 ${ }^{1}$, 채충식', 한미향' ${ }^{1}$ 권경민 ${ }^{2}$, 박지혜 ${ }^{1}$, 박경신 $^{3}$, 고영진 ${ }^{1}$

${ }^{1}$ 가톨릭대학교 서울성모병원 재활의학과, ${ }^{2}$ 가톨릭대학교 여의도성모병원 재활의학과, ${ }^{3}$ 가톨릭대학교 서울성모병원 병리과

\section{Early Electrophysiologic Findings for Polyneuropathy Associated with POEMS Syndrome: A Case Report}

\author{
So Yeon Jun ${ }^{1}$, Choong Sik Chae ${ }^{1}$, Mi-hyang Han ${ }^{1}$, Kyoung Min Kwon², \\ Jihye Park ${ }^{1}$, Gyeong Sin Park ${ }^{3}$, Young Jin Ko ${ }^{1}$ \\ Departments of ${ }^{1}$ Rehabilitation Medicine and ${ }^{3}$ Clinical Pathology, Seoul St. Mary's Hospital, College of Medicine, \\ The Catholic University of Korea, ${ }^{2}$ Department of Rehabilitation Medicine, Yeouido St. Mary's Hospital, College of Medicine, \\ The Catholic University of Korea, Seoul, Korea
}

\begin{abstract}
A female patient with incidental inguinal mass was initially diagnosed with Castleman disease (CD) via lymph node biopsy and presented paresthesia of stocking and glove patterns with weakness after two cycles of chemotherapy. Severe and diffuse sensorimotor peripheral polyneuropathy (PPNP) was revealed, and POEMS syndrome (polyneuropathy, organomegaly, endocrinopathy, monoclonal protein, skin changes) was finally diagnosed according to the diagnostic criteria. Early stages of POEMS syndrome may be misdiagnosed as other diseases such as chronic inflammatory demyelinating polyneuropathy (CIDP). Therefore, accurate diagnosis of this disease is delayed and difficult. For this reason, little early electrophysiological findings have been reported. Here we report early electrophysiological findings of POEMS syndrome, demonstrating the ambiguity of the terminal latency index delay warranting attention.
\end{abstract}

Key Words: POEMS syndrome, polyneuropathies, electromyography

Introduction

POEMS syndrome (Polyneuropathy, Organomegaly,

Received January 30, 2018

Revised April 9, 2018

Accepted April 27, 2018

Corresponding Author: Young Jin Ko

Department of Rehabilitation Medicine, Seoul St. Mary's Hospital, College of Medicine, The Catholic University of Korea, 222 Banpo-daero, Seochogu, Seoul 06591, Korea

Tel: 82-2-2258-6281, Fax: 82-2-2258-2825, E-mail: yjko@catholic.ac.kr
Endocrinopathy, Monoclonal protein, Skin changes) also called Crow-Fukase syndrome is rare systematic hematologic disorder with plasma cell dyscrasia. ${ }^{1}$ Previously, several cases of POEMS syndrome have been reported to be initially diagnosed with chronic inflammatory demyelinating polyneuropathy (CIDP) because of early clinical manifestations associated with paresthesia on distal extremities, followed by progressive distal muscle weakness. ${ }^{1,2}$ A series of 99 POEMS syndrome-confirmed cases reported that $85 \%$ of patients
Copyright $\odot$ by Korean Association of EMG Electrodiagnostic Medicine
This is an Open Access article distributed under the terms of the Creative Commons Attribution Non-Commercial License (http://creativecommons.org/licenses/by-nc/4.0) which permits unrestricted non-commercial use, distribution, and reproduction in any medium, provided the original work is properly cited. 
were initially misdiagnosed and the median time from the symptom onset to diagnosis was 13 18 months. ${ }^{3}$ The top two misdiagnoses in their study were GuillianBarre syndrome and CIDP. ${ }^{3}$ Patients with POEMS syndrome exhibit uniform demyelination presenting delayed distal latencies, slowing of conduction velocities (CV), prolonged F-wave latencies with infrequent conduction block and temporal dispersion, and a lack of sural sparing. ${ }^{1}$ However, typical electrophysiological findings remain rarely reported in the acute onset phase of associated symptoms.

Here, we report a patient, already diagnosed with
Castleman disease (CD), who revealed peripheral polyneuropathy (PPNP) through immediate electrophysiological examination after the symptom onset. Finally, she was diagnosed with POEMS syndrome.

\section{Case Report}

A 46-year-old female was admitted to the general surgery department of our hospital with a 2-month history of an incidental painless palpable mass in the right inguinal area without weight loss. Abdominal and pelvic computed tomography (CT) performed under
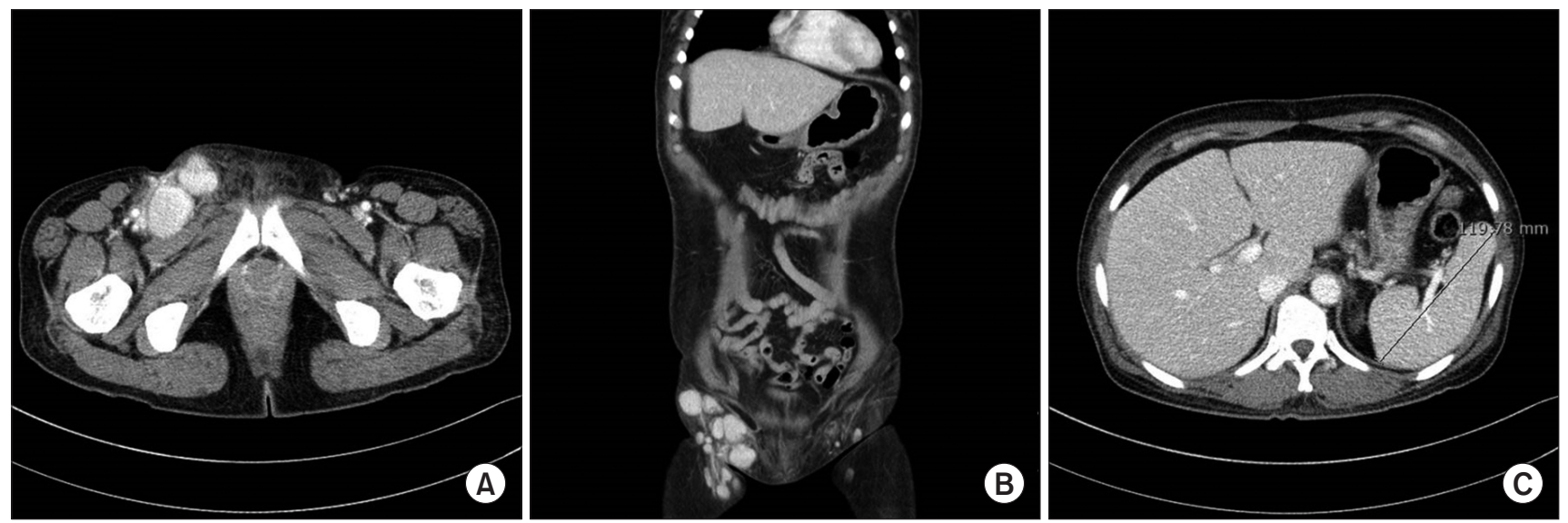

Fig. 1. Initial abdomen and pelvis computed tomography revealed multiple homogenous enhancing lymphadenopathies in right inguinal, right external iliac, right internal iliac, aortocaval, retrocaval, paraaortic, and left inguinal areas. (A) Axial view. (B) Coronal view. (C) Axial view with borderline splenomegaly with the size of $12.2 \mathrm{~cm}$ (axial) $10.4 \mathrm{~cm}$ (coronal).
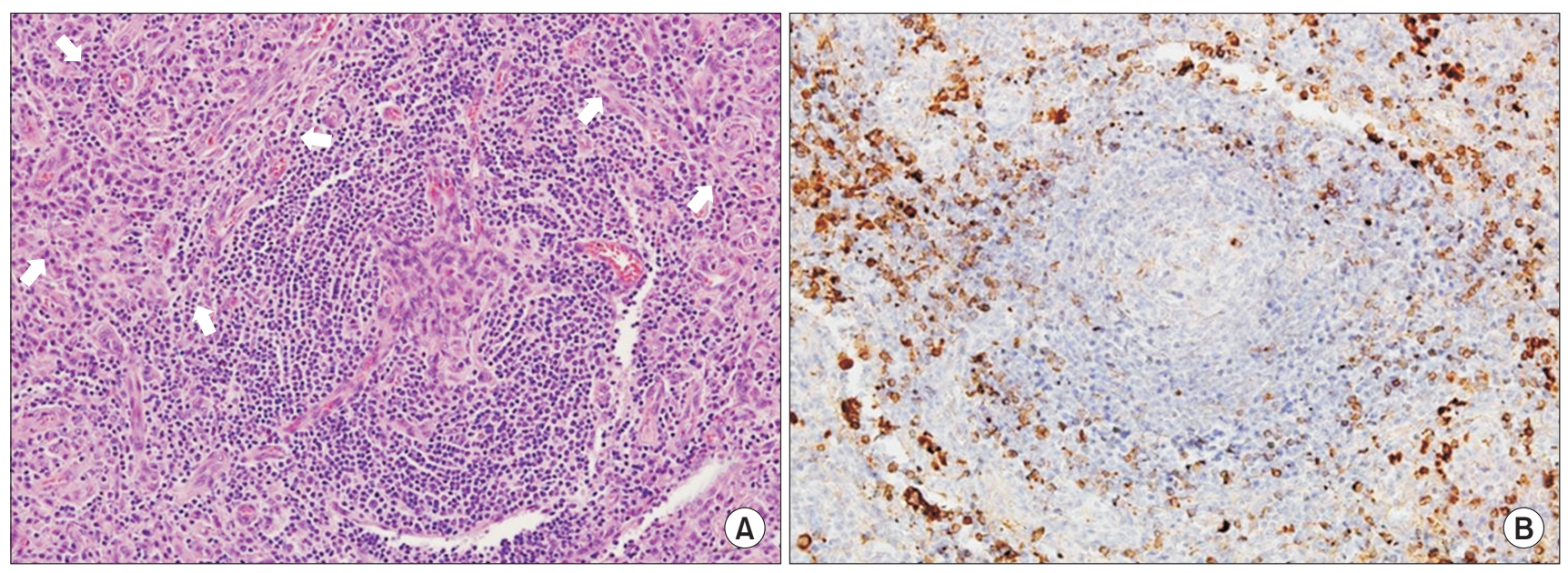

Fig. 2. Representative photomicrographs and Immunohistochemistry (IHC) expression on lymph node biopsy. (A) Hematoxylin and eosin (H\&E) stained sections (400x) show expanded interfollicular zones (arrows) with increased plasma cells. (B) IgG immunostaining (400x), numerous plasma cells were observed, most of which were positive for $\operatorname{lgG}$. 
suspicion of lymphoma revealed multiple lymphadenopathies (LAPs) in the bilateral inguinal, right external iliac, right internal iliac, aortocaval, retrocaval, and paraaortic areas with borderline splenomegaly (12.2 $\mathrm{cm} \times 10.4 \mathrm{~cm})$ (Fig. 1). An excisional biopsy at the right inguinal mass revealed multicentric plasma celltype CD (Fig. 2). A multidiscipline team for lymphoma decided serial chemotherapy, including cyclophosphamide, hydroxydaunorubicin, oncovin, and prednisone (CHOP), which is a prevalent regimen for non-Hodgkin lymphoma. After the first cycle of CHOP chemotherapy, she presented with voice hoarseness and was re- ferred to the otolaryngology unit. Stroboscopy revealed bilateral vocal cord palsy with inconsistent periodicity, incomplete glottic closure, and left vocal cord swelling. After 20 days of the second CHOP chemotherapy, she complained of a sudden-onset, symmetrical tingling sensation of stocking and glove pattern. The muscle strength of bilateral great toe extension (GTE), ankle dorsiflexion (DF), and plantarflexion (PF) were graded 3- on the Medical Research Council (MRC) grading. In addition, she had the steppage gait without definite visible muscle atrophy. Furthermore, her deep tendon reflex was hypoactive and pathological reflex was not

Table 1. Result of Initial Nerve Conduction Study and Somatosensory Evoked Potentials

\begin{tabular}{|c|c|c|c|c|c|c|}
\hline \multirow{2}{*}{ Nerve/Site } & \multicolumn{2}{|c|}{ Latency (ms) } & \multicolumn{2}{|c|}{ Amplitude $^{\dagger}$} & \multicolumn{2}{|c|}{$\mathrm{CV}(\mathrm{m} / \mathrm{s})$} \\
\hline & Right & Left & Right & Left & Right & Left \\
\hline \multicolumn{7}{|l|}{ Sensory nerve } \\
\hline Median (wrist) & $7.20 *$ & $7.65^{*}$ & $5.7^{*}$ & $6.2^{*}$ & $25.0^{*}$ & $23.9^{*}$ \\
\hline Ulnar (wrist) & $5.00 *$ & $4.75^{*}$ & $11.1^{*}$ & 15.9 & $37.3^{*}$ & $36.4^{*}$ \\
\hline Sural (calf) & NE* & NE* & NE* & NE* & & \\
\hline Superficial peroneal (ankle) & $\mathrm{NE}^{*}$ & $\mathrm{NE}^{*}$ & $\mathrm{NE}^{*}$ & NE* & & \\
\hline \multicolumn{7}{|l|}{ Motor nerve } \\
\hline Median-APB (Wrist) & $7.40 *$ & $7.05^{*}$ & $0.9 *$ & $1.8^{*}$ & & \\
\hline Median-APB (Elbow) & 14.95 & 12.70 & 0.7 & 1.4 & $27.8^{*}$ & $37.2^{*}$ \\
\hline Median-APB (Axilla) & 20.45 & 16.90 & 0.5 & 1.1 & $30.9 *$ & $44.0^{*}$ \\
\hline Ulnar-ADM (Wrist) & $4.15^{*}$ & $4.35^{*}$ & $4.5^{*}$ & $4.1^{*}$ & & \\
\hline Ulnar-ADM (Below elbow) & 8.80 & 9.00 & 3.7 & 3.6 & $32.3^{*}$ & $34.4^{*}$ \\
\hline Ulnar-ADM (Above elbow) & 12.50 & 11.95 & 3.6 & 3.4 & $37.8^{*}$ & $37.3^{*}$ \\
\hline Ulnar-ADM (Axilla) & 15.25 & 15.30 & 3.4 & 3.2 & $43.6^{*}$ & $38.8^{*}$ \\
\hline Peroneal-EDB (Ankle) & $6.15^{*}$ & $6.25^{*}$ & $0.4^{*}$ & $0.2^{*}$ & & \\
\hline Peroneal-EDB (Fibular head) & 19.15 & 24.00 & 0.2 & 0.1 & $20.8^{*}$ & $15.2^{*}$ \\
\hline Peroneal-TA (Fibular head) & $4.25^{*}$ & $5.80^{*}$ & $0.2^{*}$ & $0.4^{*}$ & & \\
\hline Peroneal-TA (Knee) & 6.90 & 9.05 & 0.2 & 0.3 & $30.2^{*}$ & $30.8^{*}$ \\
\hline Tibial-AH (Ankle) & $7.00 *$ & $7.15^{*}$ & $0.5^{*}$ & $0.4^{*}$ & & \\
\hline Tibial-AH (Popliteal) & 22.05 & 21.70 & 0.3 & 0.3 & $21.6^{*}$ & $22.0^{*}$ \\
\hline \multicolumn{7}{|l|}{ F-wave } \\
\hline Median-APB & $\mathrm{NR}^{*}$ & $\mathrm{NR}^{*}$ & $\mathrm{NR}^{*}$ & $\mathrm{NR}^{*}$ & & \\
\hline Tibial-AH & $\mathrm{NR}^{*}$ & $\mathrm{NR}^{*}$ & $\mathrm{NR}^{*}$ & $\mathrm{NR}^{*}$ & & \\
\hline \multicolumn{7}{|l|}{ H-reflex } \\
\hline Tibial nerve (Soleus) & $\mathrm{NE}^{*}$ & $\mathrm{NE}^{*}$ & $\mathrm{NE}^{*}$ & $\mathrm{NE}^{*}$ & & \\
\hline Arm SEP (Median) & & & $4.63^{\ddagger}$ & $4.79^{\ddagger}$ & & \\
\hline N20 & $41.20 *$ & $44.50 *$ & & & & \\
\hline P25 & $53.80 *$ & $58.80 *$ & & & & \\
\hline Leg SEP (Tibial) & & & $2.43^{\S}$ & $2.65^{\S}$ & & \\
\hline P37 & 61.30* & $65.40^{*}$ & & & & \\
\hline N45 & $72.70 *$ & $75.60 *$ & & & & \\
\hline
\end{tabular}

Lat: latency (motor, onset latency; sensory, peak latency), Amp: amplitude, CV: conduction velocity, NE: not evoked, NR: no response, EDB: extensor digitorum brevis, AH: abductor halluces, APB: abductor pollicis brevis, ADM: abductor digitorum minimi, TA: tibialis anterior, SEP: somatosensory evoked potential

* Indicates abnormal data based on our reference values

${ }^{\dagger}$ Amplitudes are measured in millivolt ( $\mathrm{mV}$, motor) and in microvolt $(\mu \mathrm{V}$, sensory and SEP)

${ }^{\ddagger}$ Amplitudes are measured with peak-to-peak amplitudes of N20 P25

${ }^{\S}$ Amplitudes are measured with peak-to-peak amplitudes of P37 N45 
observed.

Laboratory findings revealed normal electrolyte balance and standard thyroid function test with no evidence of Epstein-Barr virus and Cytomegalovirus infection. In addition, histopathological examination of the lymph nodes revealed no evidence of Human Herpesvirus type 8 infections. However, monoclonal gammopathy was revealed in immunoglobulin (Ig) kappaand lambda-light chain in the multiplex polymerase chain reaction (PCR) fragment analysis.

Hematologists consulted to our rehabilitation unit at 7 days after the onset of symptoms to ascertain whether clinical symptoms were due to a chemotoxic agent, such as vincristine, or were due to a clinical manifestation of CD itself. We performed an electrophysiological examination, including somatosensory evoked poten- tials (SEP). In all sampled nerves, both sensory nerve action potential (SNAP) and compound motor action potential (CMAP) revealed delayed latencies and reduced amplitudes with a considerable slowing of CV. Of note, neither F-waves nor $\mathrm{H}$ reflex was recorded (Table 1). We definitely observed prominent temporal dispersions on bilateral proximal median nerves (Fig. 3). In addition, almost all sampled muscles in the upper and lower extremities exhibited the denervation potentials (Table 2). The 1 channel SEP recording on the cortex level revealed a standard waveform and severely delayed latencies in the upper and lower extremities, implying the widespread demyelination (Table 1). Besides, severe and diffuse sensorimotor PPNP was detected with both uniform demyelination and axonal degeneration. Based on these findings, we diagnosed

A
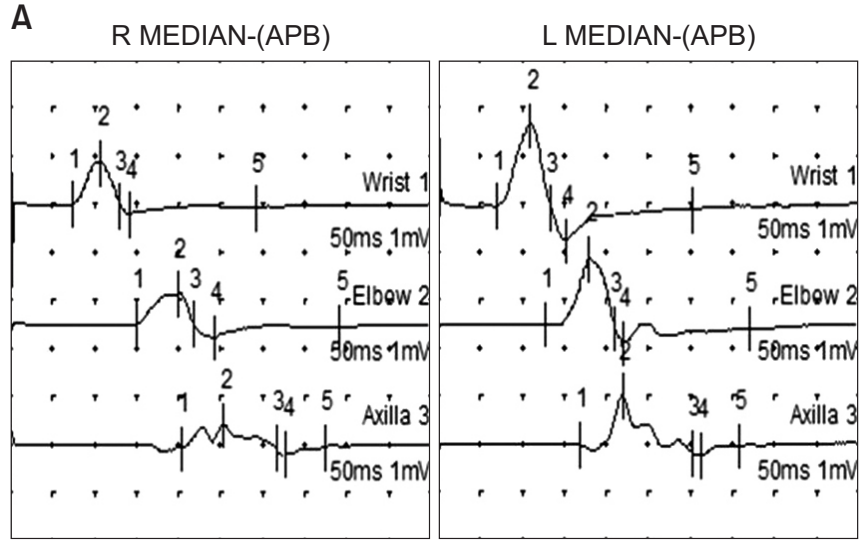

R ULNAR-(ADQ)

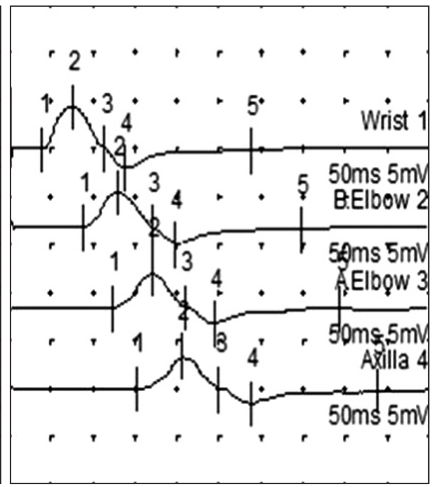

B
Needle electromyography R TBANTERIOR
Needle electromyography L GASTROCN (MED)
L ULNAR-(ADQ)

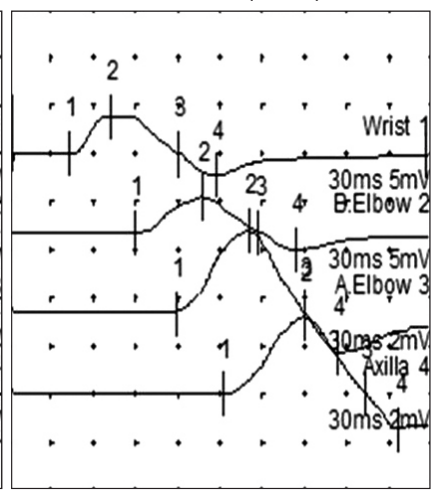

Needle electromyography L FIRST D INTEROSS

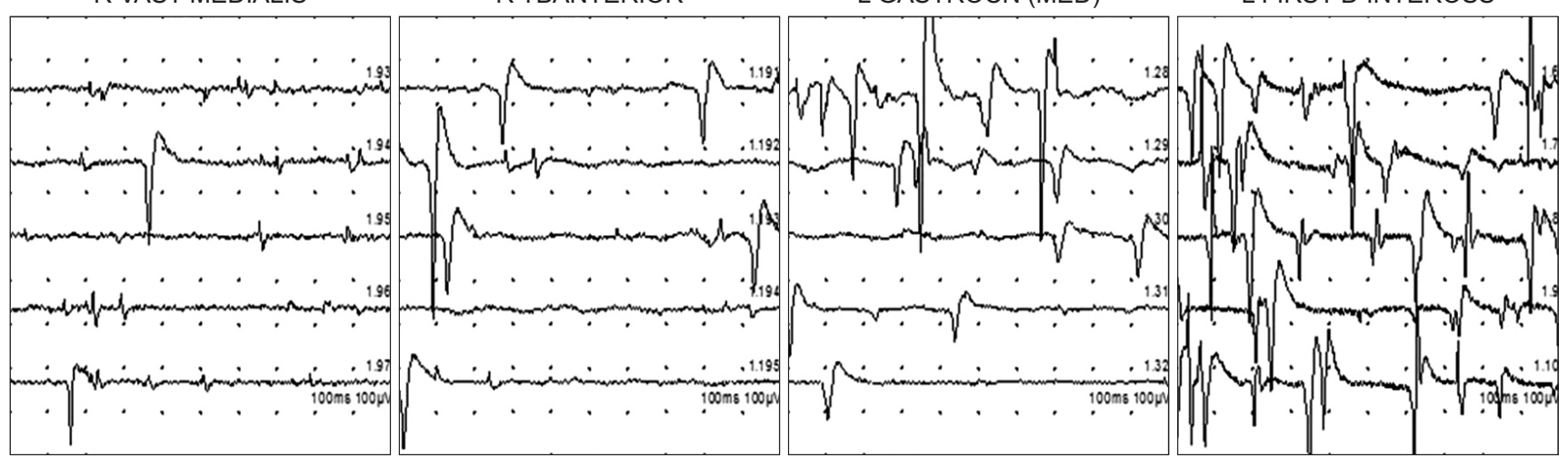

Fig. 3. (A) Temporal dispersion of bilateral median nerves and ulnar nerves in nerve conduction study recording on right abductor pollicis brevis (APB) muscle, left APB muscle of median nerves and recording on right abductor digiti minimi (ADM) muscle, recording on left ADM muscles of ulnar nerves. (B) Abnormal spontaneous activities such as positive sharp waves and fibrillation potentials in right vastus medialis, tibialis anterior, left gastrocnemius and first dorsal interossei muscles. 


\begin{tabular}{|c|c|c|c|c|c|c|c|c|}
\hline & \multicolumn{3}{|c|}{ Spontaneous activity } & \multicolumn{5}{|c|}{ Motor unit action potential } \\
\hline & $\mathrm{IA}$ & Fib & PSW & Amp & Dur. & Poly & $\begin{array}{l}\text { Interferential } \\
\text { pattern }\end{array}$ & $\begin{array}{c}\text { Recruitment } \\
\text { pattern }\end{array}$ \\
\hline B. Lumbar paraspinalis & $\mathrm{N}$ & $\mathrm{N}$ & $\mathrm{N}$ & & & & & \\
\hline B. Gluteus maximus & $\mathrm{N}$ & $\mathrm{N}$ & $1+$ & $\mathrm{N}$ & $\mathrm{N}$ & $\mathrm{N}$ & Reduced & $\mathrm{N}$ \\
\hline R. Vastus medialis & $\mathrm{N}$ & $1+$ & $2+$ & $\mathrm{N}$ & $\mathrm{N}$ & $\mathrm{N}$ & Reduced & $\mathrm{N}$ \\
\hline L. Vastus medialis & $\mathrm{N}$ & $\mathrm{N}$ & $1+$ & $\mathrm{N}$ & $\mathrm{N}$ & $\mathrm{N}$ & Reduced & $\mathrm{N}$ \\
\hline R. Tibialis anterior & $\mathrm{N}$ & $1+$ & $2+$ & $\mathrm{N}$ & $\mathrm{N}$ & $\mathrm{N}$ & Discrete & $\mathrm{N}$ \\
\hline L. Tibialis anterior & $\mathrm{N}$ & $\mathrm{N}$ & $1+$ & $\mathrm{N}$ & $\mathrm{N}$ & $\mathrm{N}$ & Discrete & $\mathrm{N}$ \\
\hline B. Gastrocnemius (MH) & $\mathrm{N}$ & $\mathrm{N}$ & $2+$ & $\mathrm{N}$ & $\mathrm{N}$ & $\mathrm{N}$ & Discrete & $\mathrm{N}$ \\
\hline B. Cervical paraspinalis & $\mathrm{N}$ & $\mathrm{N}$ & $\mathrm{N}$ & & & & & \\
\hline B. Triceps & $\mathrm{N}$ & $\mathrm{N}$ & $\mathrm{N}$ & $\mathrm{N}$ & $\mathrm{N}$ & $\mathrm{N}$ & Full & $\mathrm{N}$ \\
\hline B. Biceps & $\mathrm{N}$ & $\mathrm{N}$ & $1+$ & $\mathrm{N}$ & $\mathrm{N}$ & $\mathrm{N}$ & Full & $\mathrm{N}$ \\
\hline R. Flexor carpi radialis & $\mathrm{N}$ & $\mathrm{N}$ & $1+$ & $5 \mathrm{mV}$ & $\mathrm{N}$ & $\mathrm{N}$ & Full & $\mathrm{N}$ \\
\hline L. Flexor carpi radialis & $\mathrm{N}$ & $\mathrm{N}$ & $1+$ & $\mathrm{N}$ & $\mathrm{N}$ & $\mathrm{N}$ & Full & $\mathrm{N}$ \\
\hline R. First dorsal interossei & $\mathrm{N}$ & $\mathrm{N}$ & $1+$ & $\mathrm{N}$ & $\mathrm{N}$ & $\mathrm{N}$ & Full & $\mathrm{N}$ \\
\hline L. First dorsal interossei & $\mathrm{N}$ & $1+$ & $2+$ & $\mathrm{N}$ & $\mathrm{N}$ & $\mathrm{N}$ & Full & $\mathrm{N}$ \\
\hline R. Abductor pollicis brevis & $\mathrm{N}$ & $1+$ & $1+$ & $\mathrm{N}$ & $\mathrm{N}$ & $\mathrm{N}$ & Full & $\mathrm{N}$ \\
\hline L. Abductor pollicis brevis & $\mathrm{N}$ & $1+$ & $2+$ & $6 \mathrm{mV}$ & $\mathrm{N}$ & $\mathrm{N}$ & Full & $\mathrm{N}$ \\
\hline
\end{tabular}

IA: insertional activity, Fib: fibrillation, PSW: positive sharp wave, Amp: amplitude, Dur: duration, Poly: polyphasic pattern, N: normal, Rt: right, Lt: left, B: both, $\mathrm{MH}$ : medial head, $\mathrm{N}$ : normal

POEMS syndrome according to the diagnostic criteria: PPNP and monoclonal gammopathy as mandatory major criteria, $\mathrm{CD}$ as another major criterion, and organomegaly as a minor criterion. ${ }^{4}$ We diagnosed POEMS syndrome per the diagnostic criteria. ${ }^{2}$ Accordingly, gabapentin was prescribed to control the neuropathic pain, and chemotherapy was continued without vincristine and prednisone. Later, high-dose dexamethasone was added over 4 days with mecobalamin and folic acid. After 3 months, follow-up CT revealed partial response to chemotherapy with decreased sizes of multiple LAPs and the spleen. However, the patient exhibited minimal improvement in the tingling sensation with little change in the muscle strength, which were graded 2+ on the bilateral GTE and ankle DF and graded $3+$ on the hip flexion and knee extension on the MRC grading. After 3 months, a follow-up nerve conduction study (NCS) and electromyography (EMG) revealed a mild aggravation status compared with the initial results of reduced amplitudes of SNAPs and CMAPs.

\section{Discussion}

Based on the diagnostic criteria for POEMS syndrome, the diagnosis is adequate with three of the major criteria, including two of the necessary major criteria, including polyradiculoneuropathy and clonal plasma cell disorder, and at least one of the minor criteria. ${ }^{4}$ In our case, the patient was initially diagnosed with CD, which is one of the major criteria. CD with neuropathy may occur as part of POEMS syndrome.

The pathophysiology of POEMS syndrome remains unclear. Recently, the level of vascular endothelial growth factor (VEGF) in the plasma and serum have been shown to correlate with better clinical responses and used as a surrogate biomarker. ${ }^{5}$ An increased VEGF level was included as major criteria in the revised diagnostic criteria in 2007. In addition, interleukin (IL)-1b, tumor necrosis factor (TNF)- $\alpha$, and IL-6 levels are often increased. ${ }^{4}$ Thus, new agents, such as bortezomib, as well as lenalidomide and thalidomide, exert therapeutic responses through their anti-VEGF and anti-TNF effects. ${ }^{4}$ However, the first-line treatments are autologous peripheral blood stem cell transplantation (PBSCT) for younger patients and a combination of melphalan 
and dexamethasone (MeD) for older patients who are inappropriate for autologous PBSCT. The accurate diagnosis of POEMS syndrome is important because the 5-year overall survival rate following PBSCT was 94\%. ${ }^{6}$

Nonetheless, the diagnosis of POEMS syndrome is often delayed because the syndrome is rare and can be misdiagnosed as other neurological disorders, most commonly CIDP. ${ }^{1,2}$ Recently, two large cohort studies from the United States and Japan have reported more uniform demyelination, greater axonal loss, and higher terminal latency index (TLI) in an NCS distinguishing POEMS syndrome from CIDP. ${ }^{1,7}$ Mauermann et al. ${ }^{1}$ reported that TLI > 0.38 in the median nerve exhibited $70 \%$ sensitivity and $77 \%$ specificity in distinguishing POEMS syndrome from CIDP. In our case, the initial TLI values were 0.34 and 0.27 in the median, 0.52 and 0.47 in the ulnar, 0.63 and 0.82 in the peroneal, and 0.53 and 0.51 in the tibial nerves of the right and left sides, respectively. Although the initial TLI as an indicator was ambiguous, the 3-month follow-up of TLI was acceptable with increasing values to 0.37 and 0.42 in the right and left sides of median nerves, respectively. Our case exemplified electrophysiological findings of POEMS syndrome with very early stage, just at 7 days after the onset of symptoms, because our patient was referred for a differential diagnosis under chemotherapy targeting CD. Polyneuropathy with demyelination or axonal loss is rarely reported with single use of cyclophosphamide or doxorubicin. Most cases of polyneuropathy associated with these agents were reported when they were used in combination with vincristine. And concomitant demyelination and axonal degeneration of our case were elucidated with typical findings in POEMS syndrome because vincristine-induced PPNP typically resulted in axonal sensorimotor neuropathy. ${ }^{8}$ Furthermore, the main risk factors related to the chemotherapy induced toxic neuropathy are the dosage and duration of treatment. ${ }^{9}$ Therefore, considering that the patient's symptoms occurred after just two cycles of the CHOP regimen, the symptoms are more likely to be polyneuropathy of POEMS syndrome rather than toxic neuropathy due to chemotherapy.

Isose $S$ et al. ${ }^{10}$ reported a patient with POEMS syndrome presenting as acute polyneuropathy with electrodiagnostic features of demyelination similar to the Guillain-Barre syndrome at 28 days after the symptoms. Additionally in their review of 30 patients with POEMS syndrome, almost all cases exhibited the chronic progression of neuropathy, but unusually, there could be a rapid progression case with acute demyelinating neuropathy like their report. The clinically rapid progression with gait disturbance was associated with the presence of ascites or pleural effusion at the time of neuropathy and higher serum VEGF levels. In our case, the patient exhibited a rapid progression with an ongoing gait disturbance; however, abdominal and pelvic CT revealed neither ascites nor pleural effusion.

Diagnosing POEMS syndrome at an early stage is challenging because only one or two symptoms are observed at initial clinical manifestations. ${ }^{2}$ Previously, PPNP has been suggested as an essential item to be observed among the diagnostic criteria. ${ }^{1,11}$ Therefore, in order to diagnose without delay, it is essential to accurately detect PPNP as a main criterion. In addition, recent advancements in the understanding of the NCS and EMG attributes of POEMS syndrome could facilitate in distinguishing it from other demyelinating polyneuropathies early in the disease process. ${ }^{11}$ However, our patient reported an ambiguous TLI in the initial NCS findings and more acceptable TLI values, proposed by previous reports, in the 3-month follow-up. ${ }^{1,7}$ Thus, follow-up NCS and EMG are warranted to avoid misdiagnosis.

\section{References}

1. Mauermann ML, Sorenson EJ, Dispenzieri A, Mandrekar J, Suarez GA, Dyck PJ, et al: Uniform demyelination and more severe axonal loss distinguish POEMS syndrome from CIDP. J Neurol Neurosurg Psychiatry 2012: 83: 480-486

2. Li J, Zhou DB: New advances in the diagnosis and treatment of POEMS syndrome. Br J Haematol 2013: 161: 303-315

3. Li J, Zhou DB, Huang Z, Jiao L, Duan MH, Zhang W, et al: 
Clinical characteristics and long-term outcome of patients with POEMS syndrome in China. Ann Hematol 2011: 90: 819-826

4. Dispenzieri A: POEMS syndrome: 2017 Update on diagnosis, risk stratification, and management. Am J Hematol 2017: 92: 814-829

5. D'Souza A, Hayman SR, Buadi F, Mauermann M, Lacy MQ, Gertz MA, et al: The utility of plasma vascular endothelial growth factor levels in the diagnosis and follow-up of patients with POEMS syndrome. Blood 2011: 118: 4663-4665

6. D'Souza A, Lacy M, Gertz M, Kumar S, Buadi F, Hayman S, et al: Long-term outcomes after autologous stem cell transplantation for patients with POEMS syndrome (osteosclerotic myeloma): a single-center experience. Blood 2012: 120: 5662

7. Nasu S, Misawa S, Sekiguchi Y, Shibuya K, Kanai K, Fujimaki $\mathrm{Y}$, et al: Different neurological and physiological profiles in
POEMS syndrome and chronic inflammatory demyelinating polyneuropathy. J Neurol Neurosurg Psychiatry 2012: 83: 476-479

8. Caccia MR, Comotti B, Ubiali E, Lucchetti A: Vincristine polyneuropathy in man. A clinical and electrophysiological study. J Neurol 1977: 216: 21-26

9. Velasco R, Bruna J: Chemotherapy-induced peripheral neuropathy: An unresolved issue. Neurología (English Edition) 2010: 25: 116-131

10. Isose S, Misawa S, Kanai K, Shibuya K, Sekiguchi Y, Nasu $\mathrm{S}$, et al: POEMS syndrome with Guillan-Barre syndromelike acute onset: a case report and review of neurological progression in 30 cases. J Neurol Neurosurg Psychiatry 2011: 82: 678-680

11. Robey RC, Campus C, Ringuette B, Shumate M: POEMS syndrome: complex factors contributing to a delayed diagnosis. BMJ Case Rep 2015: 30: 10.1136/bcr-2015-213123 